\title{
The Contribution of the EMT Project toward Translator Competence Acquisition: A Balance between Theoretical and Professionally Oriented Translator Training
}

\author{
Evanthia SARIDAKI*
}

\begin{abstract}
One of the major issues addressed in the field of translation studies concerns the contribution of translation theory to translator training and the translator's profession. The basic question that is raised in the present paper regards the role of theory in translator training programmes of the European Master's in Translation (EMT) network. In the present paper, the structure of 64 translation programmes bringing the label of the EMT has been studied, focusing basically on the theoretical components of the particular programmes. To this end, the aims and content of the translation theory courses offered by the EMT programmes have been extensively investigated. More specifically, after an introduction to the competence framework as defined by the EMT, teaching objectives are analyzed to examine common elements as well as those components that differentiate one programme from the other. Other matters that have been explored are related to learning methodologies such as recommended literature, learning resources and outcomes, as well as student assessment procedure. Results have clearly shown that the theoretical component of the EMT network programmes aims basically at helping students enhance various subcompetences such as methodological, social, transcultural, and critical ones that are closely related to the practice of translation and the translating profession in order to ensure a good match between graduate theoretical knowledge and requirements of the translator's profession.
\end{abstract}

Keywords: translator training; translation competences; EMT programmes; translation theory courses; interrelationship between theory and practice

\section{Introduction}

The present paper attempts to discuss the contribution of the European Master's in Translation (EMT) of the European Union toward the status of theory in translator training. According to Luc van Doorslaer $(2013,82)$, the EMT constitutes the most important institutionalized sign that the traditional gap between theoreticians and practitioners can be overcome, since the detailed description of the competences required for high-level translators includes several components that are closely related to reflection on theoretical translation

\footnotetext{
* Dr. at Aristotle University, Thessaloniki.

E-mail: evasarid@hotmail.com; ORCID ID: https://orcid.org/0000-0002-2783-0798. (Received 11 October 2020; accepted 5 December 2020)
} 
transLogos 2020 Vol 3 Issue 2

Saridaki, Evanthia, pp. 23-40

The Contribution of the EMT Project toward Translator

matters. He refers to the following two examples out of many others, which are considered essential components of translation competence: (a) mastering the appropriate language, and (b) knowing how to identify the rules for interaction relating to a specific community, including non-verbal elements. In his words, the above competences

cannot be achieved without a thorough and critical confrontation with theoretical reflection on translation, transfer and intercultural communication. Despite existing and on-going irritation within translation practice, the impact of theoretical reflection on the practice of translation, though often indirect, is undisputable. (van Doorslaer 2013, 82)

First of all, the EMT is a quality label given to postgraduate translator training programmes that meet certain commonly accepted quality standards of translator training. The universities that offer translation programmes in line with the EMT standards and goals form the EMT network aiming to enhance student competences and provide professionally oriented training in order to ensure, according to the guiding principles of the European Master's in Translation Competence Framework 2017 (hereafter cited as EMT Competence Framework) (European Commission 2017), a good match between graduate competence and employer requirements. Sixty-three programmes from member states and one non-EU country are currently members of the EMT network holding a membership certificate and thus accepting the EMT obligations.

The EMT came out of the common interest of European higher education institutions offering translation courses at postgraduate level and the Directorate-General for Translation (DGT) of the European Commission, which recognizes the importance of the EMT to achieving excellence in translator training in Europe on the basis of the EMT competence model and employability criteria. The DGT offers support to the EMT on various levels such as organizing the EMT network meetings so as to exchange translation practices and promote research and cooperation between EMT universities.

The objectives of the EMT as defined by the new EMT Competence Framework (European Commission 2017) are:

- to promote learning and teaching of advanced translation skills in order to prepare students for lifelong learning and a lifelong career as professional translators;

- to respond to changes in translator training which are due to technological advancement; 
transLogos 2020 Vol 3 Issue 2

Saridaki, Evanthia, pp. 23-40

The Contribution of the EMT Project toward Translator

- to evaluate the quality of translator training programmes;

- to promote collaboration with institutions, professional associations, and translation companies in order to acquire comprehensive knowledge of the multidimensional nature of the translator profession;

- to allow student mobility as part of their training so as to have the opportunity to study translation in more than one academic institution; and

- to encourage discussions on pedagogical matters and educational research in the field of translation studies.

The EMT network published a framework of translator and translation competence first in January 2009. It has become one of the most important reference points in translator training not only in Europe but beyond as well. In October 2016, the framework of competences was reconsidered in the light of the changes that took place in various fields such as market needs, technological and societal changes which had a strong impact on the translation process and on student perception of the concept of translation. The new framework embodied the basic principles of the EMT network, incorporating at the same time the key competences required of future translators. The framework is based on the principle that

"translation" is a process designed to meet an individual, societal or institutional need. It also recognises that it is a multi-faceted profession that covers the many areas of competence and skills required to convey meaning (generally, but not exclusively, in a written medium) from one natural language to another, and the many different tasks performed by those who provide a translation service. (European Commission 2017, 4)

Among the aims of strategic importance as defined by the DGT is to improve "the employability of graduates of Master's degrees in translation throughout Europe" (European Commission 2017, 3). The competence framework

is based on the EMT's founding principles set out by the Expert Group in January 2009. It also takes into account the research outcomes on translation and translator competence reported by the translation studies research community and the changes that have affected the language services industry since then. (European Commission 2017, 3)

It constitutes a "simple, functional" framework so that students become aware of new challenges and adapt their practices accordingly (European Commission 2017, 2). In addition, 
transLogos 2020 Vol 3 Issue 2

Saridaki, Evanthia, pp. 23-40

The Contribution of the EMT Project toward Translator

the framework does not claim to provide a comprehensive model of all competences that graduates should acquire, but it describes a set of general and specific skills that graduates are expected to possess, meaning that individual programmes can include other competences as well which do not form part of this framework (4). Also, the framework does not define various levels for different areas of competence, assuming that programmes within the EMT network expect students to achieve the advanced level of competence required of future translators (5).

Before we distinguish the areas of the EMT Competence Framework, we need to refer to the concept of translation competence, the complex and diverse nature of which makes it difficult to provide a comprehensive definition. One of the first definitions of translation competence was proposed by Roger T. Bell as the "knowledge and skills the translator must possess in order to carry it [the translation process] out" (1991, 43). From a didactic perspective, Dorothy Kelly defines translation competence as "the set of knowledge, skills, attitudes and aptitudes which a translator possesses in order to undertake professional activity in the field" $(2005,58)$.

Other interrelated key terms are the terms 'skill,' 'competence,' 'knowledge,' and 'learning outcomes' that are accurately defined by the European Qualifications Framework for Lifelong Learning (EQF) (European Commission 2008, 11) as follows: ${ }^{1}$

- skill: "the ability to apply knowledge and use know-how to complete tasks and solve problems";

- competence: "the proven ability to use knowledge, skills and personal, social and/or methodological abilities, in work or study situations and in professional and personal development";

- knowledge: "the outcome of the assimilation of information through learning. Knowledge is the body of facts, principles, theories and practices that is related to a field of work or study";

- learning outcomes: "statements of what a learner knows, understands and is able to do on completion of a learning process, which are defined in terms of knowledge, skills and competence."

\footnotetext{
${ }^{1}$ The terms 'competence,' 'skill,' 'knowledge,' and 'learning outcomes' are used here in accordance with the European Qualifications Framework for Lifelong Learning (EQF).
} 
transLogos 2020 Vol 3 Issue 2

Saridaki, Evanthia, pp. 23-40

The Contribution of the EMT Project toward Translator

trans Dogos

A Translation Studies Journal

Competence Acquisition: A Balance between Theoretical

and Professionally Oriented Translator Training

(C) Diye Global Communications diye.com.tr|diye@diye.com.tr

Most models describing translation competence are componential models focusing on multiple components or subcompetences such as language competence, extralinguistic competence, strategic competence. According to the PACTE ${ }^{2}$ model (PACTE 2000, 101), translation competence comprises interacting subcompetences such as the bilingual subcompetence, the strategic subcompetence, the extra-linguistic subcompetence, the instrumental subcompetence, the knowledge about translation subcompetence, and the psycho-physiological components subcompetence.

The EMT Competence Framework defines five main areas of competences which should be considered as complementary and equally important to the translation service industry. However, it does not define different levels of competence for each area, assuming that master's degree programmes expect students to acquire the advanced level of competence in all five areas. The first one of these is personal and interpersonal competence area including skills such as (a) knowing how to work in a team with other experts and being able to adapt to new situations/working conditions, (b) knowing how to work under pressure and how to manage their time, stress, and deadlines, (c) knowing how to self-evaluate and continually develop their competences through personal techniques and collaborative learning. The second one is service provision competence area including the following skills: (a) knowing how to comply with professional ethics and make contacts with other translators via social media and professional associations, (b) knowing how to revise language services and strategies and suggest improvement strategies, (c) knowing how to negotiate with the client and offer a translation appropriate to the client's request, (d) knowing and implementing the quality standards applicable to the provision of a translation service. The third one is technology competence area which is defined as (a) mastering the basics of machine translation (MT) and knowing the possibilities as well as the limits of MT, (b) making effective use of search engines, corpus-based tools, text analysis tools, and computeraided translation (CAT) tools, (c) using the most recent information technology (IT) applications and adapting to new tools and IT resources. The fourth one is translation competence area which includes the three major competences - strategic, methodological, and thematic - that affect all phases of the translation procedure, from documents analysis to the

\footnotetext{
${ }^{2}$ The PACTE Group is a research group formed at the Autonomous University of Barcelona with the purpose of doing empirical and experimental research on translation competence. They have developed a model, the PACTE model, according to which translation competence comprises different interacting sub-consequences.
} 
transLogos 2020 Vol 3 Issue 2

Saridaki, Evanthia, pp. 23-40

The Contribution of the EMT Project toward Translator

final quality control procedure of the translated product. More specifically, it covers the following subcompetences: (a) knowing to analyze a source document, identifying potential problems, and defining strategies for resolving these problems, (b) evaluating the reliability of sources of information for a given task, (c) translating general and domain-specific material and producing a 'fit for purpose' translation, (d) translating various types of material for different kinds of media, using appropriate tools and techniques, (e) applying the appropriate style and any other conventions to a particular translation, (f) developing and using knowledge in specific thematic fields, (g) knowing how to proofread and revise a translation according to some standard quality standards and objectives, (h) developing the ability to analyze and justify translation choices by using the appropriate theoretical framework and mastering the appropriate metalanguage, (i) talking about one's work, techniques, and decisions. The fifth one is language and culture competence area including (a) the linguistic, (b) sociolinguistic, (c) cultural, and (d) transcultural skills that constitute the basis for advanced translation competence (European Commission 2017).

It is worth mentioning that the framework considers as a prerequisite that students should have a high level of language competence in at least two working languages in order to enter any EMT degree course in translation. However, it acknowledges that language and cultural competence in each working language can be improved and perfected during the master's degree programme (European Commission 2017, 6).

\section{Translation Theory Courses of the EMT Network Programmes: Aims and Objectives}

As far as the structure of the EMT programmes is concerned, most of them include theoretical courses that are obligatory modules, with the exception of few programmes with purely practical orientations in which no translation theory courses are taught, such as MA in Audiovisual Translation (University of Roehampton), MA in Translation (University of Vienna), and MA in Medical and Healthcare Translation (Jaume I University). Moreover, in few programmes such as MA in Specialized Translation (University of Bologna), translation theory is not taught as an autonomous course, but it constitutes part of the course Linguistics for Translators. ${ }^{3}$

\footnotetext{
${ }^{3}$ Descriptions of the translation theory courses of the present research are based on the study guides of the following EMT programmes: University of Vienna, Free Institute of Marie Haps of Belgium, Charles University, Jaume I University, University of Valladolid, Stendhal University, New Sorbonne University-Paris
} 
transLogos 2020 Vol 3 Issue 2

Saridaki, Evanthia, pp. 23-40

The Contribution of the EMT Project toward Translator

trans Dogos

A Translation Studies Journal

Competence Acquisition: A Balance between Theoretical

and Professionally Oriented Translator Training

(C) Diye Global Communications diye.com.tr|diye@diye.com.tr

Regarding the names of the theoretical modules and their implications for the content of the particular courses, apart from the names Translation Theory (Dublin City University), Introduction to Translation Theory (Riga Technical University), Contemporary Translation Theory (University of Birmingham), and Contemporary Translation Theories (Babeş-Bolyai University), the following names are used as well:

- Theoretical Foundations of Professional and Institutional Translation (University of Valladolid) and Translation Issues (University of Surrey, University of Salford): The courses aim at a more general study of the translation phenomenon. In particular, the objective of the course Translation Issues (University of Surrey) is specified as "to provide an overview of the translation phenomenon and of translation studies as an academic discipline" in the programme specification for MA in Translation. ${ }^{4}$

- Theory and Practice of Translation (University of Portsmouth): The course aims, according to the course's handbook 2019-2020, to explore the interrelationship between the theoretical and practical aspect of the translation procedure and ensure effective use of the theories learned in the course. To quote the exact words of the course description, "graduates will have an enhanced understanding of how translation theory and modes of analysis can be applied to practical text production." $"$

- Translation Studies (Catholic University of Louvain, University of Salford, University of Manchester), Translatology (Free Institute of Marie Haps of Belgium), History and Theory of Translation (Swansea University, University of Valladolid), Theoretical Concepts of Translation Studies (Aston University): The courses lay emphasis, according to their study guides, on the evolution of translation as an academic discipline and the history of translation theory. ${ }^{6}$

3, Rennes 2 University, University of Strasbourg, University of Toulouse, Dublin City University, University of Bologna, University of Trieste, Riga Technical University, University of Porto, Babeş-Bolyai University, Aston University, University of Birmingham, Durham University, University of Surrey, University of Hull, University of Leeds, University of Roehampton, University of Manchester, Newcastle University, University of Portsmouth, University of Salford, Swansea University, University of Geneva, Leipzig University, ISIT, University of Ljubljana, Constantine the Philosopher University, University of Turku, Catholic University of Louvain, Aristotle University.

4 "Translation MA - 2021 Entry," on University of Surrey's official website, accessed October 28, 2020, https://www.surrey.ac.uk/postgraduate/translation-ma.

5 "MA Translation Studies," on University of Portsmouth's official website, accessed October 29, 2020, https://www.port.ac.uk/study/courses/ma-translation-studies.

6 “Translation Studies LTRAD2001 2020-2021," on Catholic University of Louvain's official website, accessed October 20, 2020, https://uclouvain.be/en-cours-2020-ltrad2001\#; "MA-PgDip in Interpreting and Translating," 
transLogos 2020 Vol 3 Issue 2

Saridaki, Evanthia, pp. 23-40

The Contribution of the EMT Project toward Translator

As for the aims of translation theory courses, we could distinguish them as purely academic and of practical orientation. As far as the purely academic goals are concerned, according to the course descriptions taken from the study guides of the EMT network programmes, the primary goal of most courses is to familiarize students with the fundamentals of translation theory through a historical look so that they acquire the necessary theoretical background knowledge about basic concepts of translation. For instance, the expected learning outcome of the course Translatology and Culture Management (MA in Specialized Multilingual Translation, Stendhal University) is for the students to acquire "translator culture" (culture de traducteurs) — that is, academic knowledge about the history of the theory and practice of translation - and explore the changes in the cultural status of translation from ancient times to the present. ${ }^{7}$ Moreover, in some programmes such as the MA in Professional Translation for European Languages (Newcastle University), the expected learning outcome, according to the programme specification for MA in Translation Studies, is not "a simple understanding of concerns, concepts and issues in translation theory, but, mostly, a critical reflection on theoretical aspects of translation so that students are able to compare, evaluate and contrast the different theoretical approaches of translation," 8 as defined in the handbook 2019-2020 of the MA in Professional Translation for European Languages programme of Newcastle University.

As for the practical aspect of translation theory courses, the general purpose, mostly of programmes with a professional orientation (Riga Technical University, Newcastle University, University of Salford, Aristotle University), according to the information provided

educaedu, accessed September 15, 2020, https://www.educaedu.co.uk/ma-pgdip-in-interpreting-and-translatingmasters-18706.html; "MA Translation and Interpreting Studies," on University of Manchester's official website, accessed October 20, 2020, https://www.manchester.ac.uk/study/masters/courses/list/07006/ma-translation-andinterpreting-studies/; "MA in Translation," on Free Institute of Marie Haps of Belgium's official website, accessed September 23, 2020, http://www.vinci.be/fr-be/mariehaps/Pages/Etudes.aspx; “Translation and Interpreting, MA," on Swansea University's official website, accessed September 10, 2020, https://www.swansea.ac.uk/postgraduate/taught/artsandhumanities/ma-translation-interpreting/; "MA in Translation," on University of Valladolid's official website, accessed September 12, 2020, https://www.facultadtraduccionsoria.es; "Translating for Business and International Institutions," on Aston University's official website, accessed September 20, 2020, https://www.aston.ac.uk/postgraduate.

7 "Catalogue des Formations" (Training catalog), on Stendhal University's official website, accessed September 15, 2020, http://formations.univ-grenoble-alpes.fr/fr/catalogue/master-XB/arts-lettres-langues-ALL/master-languesetrangeres-appliquees-lea-program-master-langues-etrangeres-appliquees/parcours-traduction-specialiseemultilingue-subprogram-parcours-traduction-specialisee-multilingue.html.

8 "Programme Regulations and Specifications," on Newcastle University's official website, accessed September 15, 2020, https://www.ncl.ac.uk/regulations/programme/2020-2021/. 
transLogos 2020 Vol 3 Issue 2

Saridaki, Evanthia, pp. 23-40

The Contribution of the EMT Project toward Translator

by their study guides, ${ }^{9}$ is to allow students to obtain a detailed understanding of the process of translation so as to be able to identify potential translation problems and select appropriate strategies to solve them. In other words, they aim to help students demonstrate a critical awareness of the proposed translation methodologies so that they can accept or even reject them when they are asked to take translation decisions. To specify, among the expected learning outcomes of the course Introduction to Translation Theory (MA in Technical Translation, Riga Technical University) is that "students will be able to analyse, identify, and apply practically in the translation process the adequate translation strategy and precise professional terminology." 10 Also, the specific objective of the course Translation Theory (MA in Professional Translation for European Languages, Newcastle University), is "to cultivate student ability of self-direction and originality in tackling and solving problems, decision-making in complex and unpredictable situations, and the ability to act autonomously in planning and implementing tasks at a professional level." 11

Another practical goal is to enable students to apply relevant conceptual tools when tackling specific translation tasks and develop a theoretical framework for analyzing and discussing translation decisions so that they can reflect on the quality of both their own translation products and those of other colleagues. For instance, the course Translation Issues of the programme MA in Translation (University of Surrey) defines among its goals "to develop a theoretical framework for analyzing and justifying translation decisions," 12 while according to the expected learning outcomes of the course Theory and Practice of Translation

\footnotetext{
9 "Professional Master Study Programme 'Technical Translation,"” on Riga Technical University's official website, accessed October 20, 2020, https://www.rtu.lv/en/feth/studies-feth/master-professional-studyprogramme--technical-translation; "Programme Regulations and Specifications," on Newcastle University's official website, accessed September 15, 2020, https://www.ncl.ac.uk/regulations/programme/2020-2021/; "MAPgDip in Interpreting and Translating," educaedu, accessed September 15, 2020, https://www.educaedu.co.uk/ma-pgdip-in-interpreting-and-translating-masters-18706.html; "MA in Conference Interpreting and Translation," on Aristotle University's official website, accessed October 30, 2020, http://gp.enl.auth.gr/en/postgraduate/msc-5.

10 "Professional Master Study Programme 'Technical Translation,"” on Riga Technical University's official website, accessed October 20, 2020, https://www.rtu.lv/en/feth/studies-feth/master-professional-studyprogramme--technical-translation.

11 "Programme Regulations and Specifications," on Newcastle University's official website, accessed September 15, 2020, https://www.ncl.ac.uk/regulations/programme/2020-2021/.

12 "Translation MA - 2021 Entry," on University of Surrey's official website, accessed October 28, 2020, https://www.surrey.ac.uk/postgraduate/translation-ma.
} 
transLogos 2020 Vol 3 Issue 2

Saridaki, Evanthia, pp. 23-40

The Contribution of the EMT Project toward Translator

of the programme MA in Translation Studies (University of Portsmouth), students will be able to "critically evaluate both their own and existing published translations."13

The role of ideology in the translating procedure is also studied in the EMT programmes so that students are able to comprehend both the ideological dimension of translation and the role of the translator as ideological manipulator. The translation of ideology, with the focus on how ideology is handled in the text to be translated as well as the extent to which translators can or should mediate, is included in the curriculum of some EMT programmes. For instance, a specific goal of the course Theory of Translation of the programme MA of Interpreting and Translation Studies (Monash University in collaboration with University of Trieste) is to help students "explore all the possibilities of ideological manipulation in the time of rewriting the target text." 14

Contemporary translation studies are also aware of the need to examine in depth the relationship between the production of knowledge in a given culture and its transmission, relocation, and reinterpretation in the target culture. Modern approaches view translation not as a mere transcoding process, but as a form of action across cultures, as a cross-cultural event (Arrojo 2005; Venuti 1995; Bassnett-McGuire 1980). According to the study guides of the EMT programmes, the intercultural stage of translator training numbers among its aims student sensitization to the cultural differences between societies and their implications for translating, since the acquisition of cultural and transcultural knowledge and skills constitutes the basis for advanced translation competence. More specifically, one of the goals of the course Theoretical Translation Issues of the programme MA in Translation (University of Surrey) is defined as

the study of the role culture plays in translation, focusing mainly on the linguistic and cultural resources employed by translators in their attempt to serve as mediators of messages, thus helping in the construction of identities as well as changing the recipients' behavior and world views. ${ }^{15}$

Another key issue that is raised in the field of translator training is the professional role of the translator, his responsibilities, and the ethics of translation practice. A specific

\footnotetext{
13 "MA Translation Studies," on University of Portsmouth's official website, accessed October 29, 2020, https://www.port.ac.uk/study/courses/ma-translation-studies.

14 "Master of Interpreting and Translation Studies," on Monash University's official website, accessed September 18, 2020, https://handbook.monash.edu/2021/courses/A6007.

15 "Translation MA - 2021 Entry," on University of Surrey's official website, accessed October 28, 2020, https://www.surrey.ac.uk/postgraduate/translation-ma.
} 
transLogos 2020 Vol 3 Issue 2

Saridaki, Evanthia, pp. 23-40

The Contribution of the EMT Project toward Translator

objective of the Translation Theory course of the programme MA in Professional Translation for European Languages (Newcastle University) is to help students "acquire a good knowledge of what it means to be a translating professional, in terms not only of practical techniques, but also of attitudes and ethics." 16

Among the specific professional skills to be developed by translation students are mentioned the following (Newcastle University, University of Surrey, Aristotle University, University of Portsmouth, Aston University): career-management skills suitable for entry to the translating profession; the ability to manage time, make plans, and set priorities to achieve a complex objective; the ability to critically analyze their own and others' translating processes; the ability to work with others as part of a team; the ability to reflect on the translating experience in more general and theoretical terms and to integrate practical with professional and theoretical insights; development of academic and life skills, such as research design and methodology, and synthesizing and analyzing information and data; mastering the appropriate metalanguage (to talk about one's work, strategies, and decisions); knowing how to comply with professional ethics.

Finally, some translation theoretical modules wish to emphasize the development of thematic competence-that is, the acquisition of knowledge in specialist fields and applications as necessary cognitive background for specific types of translation. The course Theory and Practice of Translation of the MA in Translation Studies (University of Portsmouth) sets as one of its goals "to provide opportunities for students to study specific scientific areas so that they get familiarized with the relevant terminology and develop an appropriate expertise in different types of translation." ${ }^{17}$ Moreover, in the course Translatology and Quality Management (MA in Specialized Multilingual Translation, Stendhal University), students are encouraged to "reinforce their knowledge in specific thematic domains so that they enhance their ability to translate different types of domainspecific and situation-specific types of translation." 18

\footnotetext{
16 "Programme Regulations and Specifications," on Newcastle University's official website, accessed September 15, 2020, https:/www.ncl.ac.uk/regulations/programme/2020-2021/.

17 "MA Translation Studies," on University of Portsmouth's official website, accessed October 29, 2020, https://www.port.ac.uk/study/courses/ma-translation-studies.

18 "Catalogue des Formations" (Training catalog), on Stendhal University's official website, accessed September 15, 2020, http://formations.univ-grenoble-alpes.fr/fr/catalogue/master-XB/arts-lettres-langues-ALL/master-languesetrangeres-appliquees-lea-program-master-langues-etrangeres-appliquees/parcours-traduction-specialiseemultilingue-subprogram-parcours-traduction-specialisee-multilingue.html.
} 
transLogos 2020 Vol 3 Issue 2

Saridaki, Evanthia, pp. 23-40

The Contribution of the EMT Project toward Translator

trans Dogos

A Translation Studies Journal

Competence Acquisition: A Balance between Theoretical

and Professionally Oriented Translator Training

(C) Diye Global Communications diye.com.tr|diye@diye.com.tr

\section{Translation Theory Courses of the EMT Network Programmes: Structure and}

\section{Content}

As far as the content of the theoretical component of the EMT programmes is concerned, the basic conclusions drawn out of the study guides of the translation theory courses of the EMT programmes are summarized in this section.

Translation theory courses provide an overview of the emergence of translation studies as an academic discipline and an introduction to controversial debates concerning basic concepts of translation studies and approaches to translation. They also provide a brief historical look of the development of translation theory, from classical Western and early modern periods to theories in the twentieth century, with the main focus on contemporary, target-oriented approaches.

Particular emphasis is given to the study of linguistics-based and textlinguistic approaches to translation, functionalist theories of translation, as well as the cultural, philosophical, and sociological approaches to the process of translation.

More specifically, linguistics-based approaches to translation constitute a basic introductory element of translation theory courses so that students are able to realize the impact of modern linguistics on the theoretical and practical aspects of translation. Some of the key concepts that are examined are 'equivalence,' 'fidelity,' 'faithfulness,' 'translatability,' and 'translation procedure.' In addition, the types of linguistic meaning and their transference in the process of translation are analyzed so that students are stimulated to think about the changes in the idea of meaning and how linguistic meaning widens to take in a variety of contextual factors. ${ }^{19}$

Textlinguistic approaches to translation which view translation as text production are included in most translation theory courses of the EMT network members, such as Translation Studies (MA in Translation and Interpreting Studies, University of Manchester), Theoretical Concepts of Translation Studies (MA in Translating for Business and International Institutions, Aston University). Basic concepts that are covered are 'text typology,' 'genre,'

\footnotetext{
${ }^{19}$ Francesca Bartrina $(2005,181)$ stresses the need of reflecting upon the concept of meaning, mentioning that all types of translation have as their starting point certain attitudes about meaning, be these attitudes conscious or unconscious.
} 
transLogos 2020 Vol 3 Issue 2

Saridaki, Evanthia, pp. 23-40

The Contribution of the EMT Project toward Translator

trans Dogos

A Translation Studies Journal

Competence Acquisition: A Balance between Theoretical

and Professionally Oriented Translator Training

(C) Diye Global Communications diye.com.tr|diye@diye.com.tr

'intertextuality,' and 'convention.' They also focus on the terms 'cohesion' and 'coherence' that are closely related to the concept of intertextuality.

Functionalist theories of translation, according to which translation is a purposeful activity performed by experts (Vermeer 1989; Nord 1997), constitute the basic component in most translation theory courses of translation programmes, such as MA in Specialized Translation (University of Bologna), MA in Interpreting and Translation Studies (University of Trieste), MA in Translation and Interpreting Studies (University of Manchester). Concepts such as 'function,' 'purpose,' 'skopos,' 'translational action,' 'translation problem,' 'translation strategy,' and 'loyalty' are some of the key concepts related to the functionalist approach of the particular programmes.

The psycholinguistic model, which describes the cognitive and emotional aspects of the translation process, constitutes one of the components in translation students' theoretical training. Think-aloud protocol techniques and other uses of the translator's verbalized selfcommentary are examined so that students understand the factors that arise during the decision-making procedure, from source and target language textual constraints to audience design. One of the main goals of the course Translation Theory (MA in Translation Studies, Dublin City University) is to explore the cognitive aspect of translation and its impact on the translator's profession.

Moreover, postmodern and postcolonial theories are examined, focusing mainly but not exclusively, on concepts such as 'ideology,' 'gender,' 'power,' and 'ethics.' The role of ideology in the translating procedure, the extent to which translator can or should mediate, and the position of power that the practice of translation entails are some of the issues that are raised in the courses Theory of Translation (MA in Interpreting and Translation, University of Bologna), Translation Theory (MA in Translation Studies, Dublin City University), and Introduction to Translation (MA in Translation Studies, University of Birmingham).

Another theoretical issue which is raised concerns the cultural dimension of translation and, more particularly, the translation problems that are due to cultural differences so that students develop the skill to evaluate cultural gaps between texts and bridge them sufficiently. Some of the courses which focus on the cultural references employed by translators in their attempt to serve as mediators of messages are Translation Issues (MA in Translation, University of Surrey), Introduction to Translation Theory (MA in Translatology, 
transLogos 2020 Vol 3 Issue 2

Saridaki, Evanthia, pp. 23-40

The Contribution of the EMT Project toward Translator

Leipzig University), and Translation Studies (MA in Translation, Catholic University of Louvain).

More specifically, translation is viewed as "the representation of the other" 20 in the programme MA in Translating for Business and International Institutions (Aston University), and the translator is considered as "an expert in transcultural communication" 21 in the programme MA in Translatology (Leipzig University). Among the key concepts that are included in the curriculum of the particular courses are 'the cultural turn,' 'translating the other,' 'translator's visibility,' 'foreignization,' and 'domestication.'

A special emphasis is laid on the study of the social aspect of translation and the variety of tasks translators are being asked to perform as members of a sociocultural community called upon to interact with. Some key issues that are discussed concern the social role of translators as members of the translation community and other social networks, their duties and responsibilities as social agents, and translators as shapers of the political, cultural, and intellectual life of society through the study of the sociological turn translation studies has taken, following the cultural turn of the 1980s and the 1990s. The social role of the translator is stressed in most programmes that are members of the EMT, specifically in the programmes Professional and Institutional Translation (University of Valladolid), MA in Professional Translation for European Languages (Newcastle University), MA in Translation Studies (University of Portsmouth), and MA in Translation (University of Surrey).

Furthermore, among the components that are stressed in most theoretical courses are the concept of professionalization of translation and the basic skills required for the translating profession so that students get familiarized with the translator's workplace and, mostly, are able to consider and respect the ethical issues relating to their future professional career.

\section{Teaching Methods and Learning Activities}

As far as teaching methods are concerned, the teaching strategies sections of the examined study guides mostly include the following: lectures and seminars; whole-class,

\footnotetext{
20 "Translating for Business and International Institutions," on Aston University's official website, accessed September 20, 2020, https://www.aston.ac.uk/postgraduate.

21 “Translatology MA," on Leipzig University's official website, accessed September 20, 2020, https://www.unileipzig.de/en/studying/prospective-students/courses-of-study/degree-programme/course/show/translatologie-ma/.
} 
transLogos 2020 Vol 3 Issue 2

Saridaki, Evanthia, pp. 23-40

The Contribution of the EMT Project toward Translator

small group, and pair work activities; and learning activities which include (a) directed and undirected reading, (b) participation in group and class critical discussions based on literature review and student presentation, (c) text analysis, translation criticism, and comparisons of different theories studied, (d) short exercises involving data analysis and evaluation of the literature, (e) planning, designing, and executing a piece of rigorous enquiry in the form of a research project.

Students' progresses towards the learning outcomes are measured by means of:

- performance in tutorial discussions based on students' reading of relevant literature for specific topics;

- oral presentations that critique a certain contemporary theory or a theoretical issue;

- written examination testing students' knowledge of contemporary theories and theoretical models (University of Surrey, University of Southampton, University of Birmingham: written exams as assessment mode);

- short essays as critical reviews of key concepts or approaches to translation studies based on literature review (Riga Technical University: two short essays as critical reviews of basic theoretical approaches to translation); and

- extended essays on a theoretical topic that should demonstrate an ability to conduct independent research to be submitted at the end of the theoretical course (University of Manchester: extended essay of 3,000 words on a theoretical issue, Aston University: extended essay of 5,000 words on a theoretical topic).

\section{Conclusions}

In brief, the present research has shown that the theoretical component in the EMT network programmes aims for students to acquire a sophisticated understanding of how translation theory and modes of analysis can be applied to practical text production. More specifically, the general objectives of theoretical translator training in postgraduate programmes that bear the label of the EMT could be summarized as follows:

- knowledge acquisition in fundamental theoretical concepts and models of translation; 
transLogos 2020 Vol 3 Issue 2

Saridaki, Evanthia, pp. 23-40

The Contribution of the EMT Project toward Translator

- ability to critically explain and analyze their translation decisions as well as evaluate translation quality both of their own work and that of other professionals;

- student ability to choose from and use a wide range of strategies and textual solutions to tackle different translating tasks and translation problems;

- understanding of the cultural context of translation and cultural competence development in order to identify problems which are due to cultural differences between societies and evaluate solutions with reference to translation theory;

- critical understanding of the social constraints and consequences of translation, as well as self-awareness acquisition regarding the multidimensional role translators are asked to play in modern societies;

- awareness development regarding the ideological dimension of translation and the role of the translator as an ideological mediator;

- student familiarization with current professional practices and the working environment in which translators operate; and

- interpersonal competence development in order to be able to collaborate with other agents involved in the translation process (clients, authors, fellow-translators, and other specialists) and manage these relationships in accordance with professional principles and ethics.

What is suggested through the present research is that the theoretical component of translator training programmes be reevaluated, based on the EMT's founding objectives, so as to adopt a holistic and professionally oriented approach and cover a wide range of pursuits in order to assist the future translator to reflect upon the translation phenomenon and to suggest strategies and solutions on common translation problems. Consequently, it is proposed that the aims of translation students' theoretical training be redefined so that it acquires to a higher degree practical orientation in order to correspond to the multidimensional role contemporary translators perform in modern society.

As to suggestions for further research, future researchers could conduct research to investigate translation students' attitudes on the role and usefulness of theoretical training for the translating profession. Also, it could be quite interesting to conduct comparative research in order to investigate similarities and differences of attitude concerning the role of translation 
transLogos 2020 Vol 3 Issue 2

Saridaki, Evanthia, pp. 23-40

The Contribution of the EMT Project toward Translator

transDogos

Competence Acquisition: A Balance between Theoretical

A Translation Studies Journal and Professionally Oriented Translator Training

(C) Diye Global Communications diye.com.tr|diye@diye.com.tr

theory between self-taught translators and translators having pursued academic studies on translation. 
transLogos 2020 Vol 3 Issue 2

Saridaki, Evanthia, pp. 23-40

The Contribution of the EMT Project toward Translator

\section{References}

Arrojo, Rosemary. 2005. "The Ethics of Translation in Contemporary Approaches to Translator Training." In Training for the New Millennium: Pedagogies for Translation and Interpreting, edited by Martha Tennent, 225-245. Amsterdam: John Benjamins.

Bartrina, Francesca. 2005. "Theory and Translator Training." In Training for the New Millennium: Pedagogies for Translation and Interpreting, edited by Martha Tennent, 177-189. Amsterdam: John Benjamins.

Bassnett-McGuire, Susan. 1980. Translation Studies. London: Methuen.

Bell, Roger T. 1991. Translation and Translating: Theory and Practice. London: Longman.

Doorslaer, Luc van. 2013. "Impact of Translation Theory." In Handbook of Translation Studies, edited by Yves Gambier and Luc van Doorslaer, 4:77-83. Amsterdam: John Benjamins.

European Commission. 2008. The European Qualifications Framework for Lifelong Learning $(E Q F)$. Luxembourg: Office for Official Publications of the European Communities. http://relaunch.ecompetences.eu/wp-content/uploads/2013/11/EQF_broch_2008_en.pdf.

2017. European Master's in Translation Competence Framework 2017. https://ec.europa.eu/info/sites/info/files/emt_competence_fwk_2017_en_web.pdf.

Kelly, Dorothy. 2005. A Handbook for Translator Trainers: A Guide to Reflective Practice. Manchester: St. Jerome.

Nord, Christiane. 1997. Translating as a Purposeful Activity: Functionalist Approaches Explained. Manchester: St. Jerome.

PACTE. 2000. "Acquiring Translation Competence: Hypotheses and Methodological Problems of a Research Project." In Investigating Translation: Selected Papers from the 4th International Congress on Translation, Barcelona, 1998, edited by Allison Beeby, Doris Ensinger, and Marisa Presas, 99-106. Amsterdam: John Benjamins.

Venuti, Lawrence. 1995. The Translator's Invisibility: A History of Translation. London: Routledge.

Vermeer, Hans J. 1989. "Skopos and Commission in Translational Action." In Readings in Translation Theory, edited by Andrew Chesterman, 173-200. Helsinki: Finn Lectura. 